\title{
Coexistence of Celiac Disease and Systemic Lupus Erythematosus: A Case Report
}

\author{
Jaouad Yousfi $^{1 *}$, Soukaina Oumlil ${ }^{1}$, Laila Benjilali ${ }^{1}$, Lamiaa Essaadouni $^{1}$ \\ ${ }^{1}$ Department of Internal Medicine, University Hospital of Mohammed VI, Marrakesh, Morocco \\ Article History \\ Received: 14.01 .2021 \\ Accepted: 27.02 .2021 \\ Published: 17.03 .2021 \\ Journal homepage: \\ Abstract: Celiac disease (CD) is a chronic inflammatory disorder of the small intestine \\ triggered by the ingestion of gluten. It has been associated with auto-immune disorders. \\ Although many similarities exist between the pathogenesis of $\mathrm{CD}$ and systemic lupus \\ erythematosus (SLE), their association has been rarely reported. We describe a case of a 23 - \\ year-old woman diagnosed with CD, and one year later developed SLE. \\ Keywords: Coexistence, Celiac Disease, Lupus Erythematosus.
}

https://www.easpublisher.com

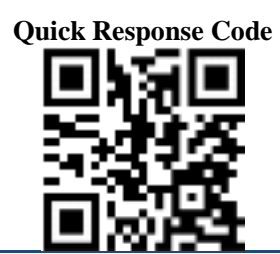

Copyright (C) 2021 The Author(s): This is an open-access article distributed under the terms of the Creative Commons Attribution 4.0 International License (CC BY-NC 4.0) which permits unrestricted use, distribution, and reproduction in any medium for non-commercial use provided the original author and source are credited.

\section{INTRODUCTION}

Systemic lupus erythematosus (SLE) and celiac disease (CD) are complex and clinically heterogeneous autoimmune disorders. Their pathogeneses is still not completely understood ; genetic and environmental factors are implicated [1-3]. SLE involves the gastrointestinal tract which is well documented [4] but its association with $\mathrm{CD}$ is rare [5, 6]. Nevertheless, some data suggest that patients with SLE develop CD and vice versa, highlighting a possible association between these diseases [3,7]. We report thecase of a 23-year-old woman with $\mathrm{CD}$, who developed SLE one year after the diagnosis.

\section{Case Presentation}

A 23-year-old woman presented with pallor, abdominal pain, diarrhea, and steatorrhea and weight loss. Physical examination showed meteorism, bilateral leg edema and muscle atrophy.

The laboratory evaluation revealed abnormal results, which included iron deficiency anemiaat $6 \mathrm{~g} / \mathrm{dl}$, hypocholesterolemia at $0,6 \mathrm{~g} / \mathrm{l}$, and hypoalbuminemia at $20 \mathrm{~g} / \mathrm{l}$. IgA anti-endomysial antibodies were positive (1/10). While anti-tissue transglutaminase antibodies (IgA and IgG) and IgGanti-endomysial antibodies were negative. Mucosal histopathology revealed villous atrophy, classified as $3 \mathrm{~A}$ according to Marsh's scale [8].
The diagnosis of $\mathrm{CD}$ was established, and a gluten-free diet was initiated. The six months follow-up showed a resolution of gastrointestinal symptoms and a weight gain. Additionally, laboratory parameters were within normalrange. One year after, the patient presented with polyarthralgia, photosensitivity, alopecia, ascites and lymphopenia $\left(700\right.$ cells $\left./ \mathrm{mm}^{3}\right)$. Serum anti-nuclear antibodies were positive with a titer of 1/160 anda homogeneous pattern. The titer of antidsDNA was high at $55 \mathrm{IU} / \mathrm{l}$. The kidney function and cardiac exploration did not show any abnormality. The diagnosis of SLE associated with CD was made, and the patient started antimalarial drugs in association with oral prednisone $20 \mathrm{mg} /$ dayfollowed by a gradual taper. At two-year follow-up, a clinical remission was achieved, gastro-intestinal symptoms were improved and the laboratory parameters were normal.

\section{DisCUSSION}

The frequency of malabsorption in SLE is estimated at $10 \%$.It is certainly underestimated due to the small number of studies [9]. Gastrointestinal manifestations are commonly presented in up to $50 \%$ of SLE patients [10], and includemesenteric arteritis, intestinal perforation and obstruction, ascites, peritonitis, enteritis, ulcerative colitis, pancreatitis, esophageal and hepatic involvement $[4,5]$. In contrast, about $50 \%$ of adults with $\mathrm{CD}$ have extra-intestinal 
manifestations; such as iron deficiency anemia, osteoporosis, infertility, cerebellar ataxia, and peripheral neuropathy [11]. Many autoimmune diseases can coexist in a single patient. However, the association of SLE with CD is still unclear [6]. A combination of histology, serology, morphometry and HLA typing may be helpful in equivocal cases [12].

Several theories have been proposed to explain this association, including the duration of exposure to gluten which would increase the risk of developing autoimmune diseases [13], and a genetic predisposition (HLA B8 DR3) [9]. High frequency of histocompatibility antigens HLA-DR3 is observed in both CD and SLE $[2,5,14,15]$. Likewise, SLE is associated in 40 to $70 \%$ of cases with HLA-DR3 [15].

Mader et al. reported astudy of 21 SLE patients. A history of abdominal pain and occasional diarrhea was elicited in 2 patients. In one of them, histologic examination revealed flattened and deformed villi with an inflammatory infiltrate [10]. The retrospective study of Benghorbal et al. enrolled 340 patients with SLE. Six presented with CD. The mean age at diagnosis of the association SLE-CD was 28 years (16-47 years). CD occurred ten and twenty-three years before SLE respectively, in two cases. CD occurred concomitantly in four cases. The laboratory finding showedmalabsorption. Mucosal histopathology revealed villous atrophy, classified as 4 according to Marsh's scale in two cases, stage 3 in one and stage 2 in two, and was normal in one case. All the patients were tested positive for antigliadin, anti-endomysial and antitransglutaminase antibodies. Four patients had a cutaneous and articular form of SLE without visceral involvement. Lupus nephritis occurred in one case [16].

Zitouni et al. reported five cases over a 4-year period. CD and SLE occurred concomitantly in one patient, whereas CD precededSLE in one patient and was diagnosed afterwardsin the remaining 3 patients. Villous atrophy on duodenal biopsy specimens with a favorable response to a gluten-free diet was noted in all the 5 patients. Only 4 patients had positive serological tests for celiac disease and only three had abdominal symptoms [17].

Due to its rarity, the association of $\mathrm{CD}$ with SLE is considered by some authors to be fortuitous. The study of Rensch et al. included 103patients with SLE , who were tested for the serological presence of $\operatorname{IgA}$ and $\operatorname{IgM}$ antigliadin and $\operatorname{IgA}$ antiendomysial antibodies. Those with positive serology underwent esophagogastroduodenoscopy with duodenal mucosal biopsy.Twenty-four patients $(23.3 \%)$ tested positive for antigliadin antibody. None of them were found to have endoscopic or histological evidence of $\mathrm{CD}$, making the false positive rate of antigliadin antibody $23 \%$. According to the authors of this study, there seems to be no association between CD and SLE since false positive antigliadin antibodies in patients with SLE is common [5].

\section{CONCLUSION}

The association between systemic lupus erythematosusand celiac disease deserves the attention of researchers. Further researchesare needed in order to determine the true prevalence of this coexistence.

\section{REFERENCES}

1. Hrycek, A., Siekiera, U., Cieślik, P., \& Szkróbka, W. (2005). HLA-DRB1 and-DQB1 alleles and gene polymorphisms of selected cytokines in systemic lupus erythematosus. Rheumatology international, 26(1), 1-6.

2. Komatireddy, G. R., Marshall, J. B., Aqel, R., Spollen, L. E., \& Sharp, A. G. C. (1995). Association of systemic lupus erythematosus and gluten enteropathy. Southern medical journal, 88(6), 673-676.

3. Hadjivassiliou, M., Sanders, D. S., Grünewald, R. A., \& Akil, M. (2004). Gluten sensitivity masquerading as systemic lupus erythematosus. Annals of the rheumatic diseases, 63(11), 1501-1503.

4. Varkel, Y., Braester, A., Suprun, H., Nusem, D., \& Horn, Y. (1989). Simultaneous occurrence of systemic lupus erythematosus and coeliac diseaselike features. Postgraduate medical journal, 65(766), 600-602.

5. Rensch, M. J., Szyjkowski, R., Shaffer, R. T., Fink, S., Kopecky, C., Grissmer, L., ... \& Kadakia, S. (2001). The prevalence of celiac disease autoantibodies in patients with systemic lupus erythematosus. The American journal of gastroenterology, 96(4), 1113-1115.

6. Courtney, P. A., Patterson, R. N., Lee, R. J. E., \& McMillan, S. A. (2004). Systemic lupus erythematosus and coeliac disease. Lupus, 13(3), 214.

7. Mirza, N., Bonilla, E., \& Phillips, P. E. (2007). Celiac disease in a patient with systemic lupus erythematosus: a case report and review of literature. Clinical rheumatology, 26(5), 827-828.

8. Marsh, M. N. (1992). Gluten, major histocompatibility complex, and the small intestine: a molecular and immunobiologic approach to the spectrum of gluten sensitivity ('celiac sprue'). Gastroenterology, 102(1), 330-354.

9. Marsh, M. N. (1992). Gluten, major histocompatibility complex, and the small intestine: a molecular and immunobiologic approach to the spectrum of gluten sensitivity ('celiac sprue'). Gastroenterology, 102(1), 330-354.

10. Mader, R., Adawi, M., \& Schonfeld, S. (1997). Malabsorption in systemic lupus erythematosus. Clinical and experimental rheumatology, 15(6), 659-661. 
11. Briani, C., Zara, G., Alaedini, A., Grassivaro, F., Ruggero, S., Toffanin, E., ... \& Battistin, L. (2008). Neurological complications of celiac disease and autoimmune mechanisms: a prospective study. Journal of neuroimmunology, 195(1-2), 171175.

12. Murdock, A. M., \& Johnston, S. D. (2005). Diagnostic criteria for coeliac disease: time for change?. European journal of gastroenterology \& hepatology, 17(1), 41-43.

13. Ventura, A., Magazzù, G., \& Greco, L. (1999). Duration of exposure to gluten and risk for autoimmune disorders in patients with celiac disease. Gastroenterology, 117(2), 297-303.

14. Keuning, J. J., Pena, A. S., Van Hooff, J. P., Van Leeuwen, A., \& Van Rood, J. J. (1976). HLA-DW3 associated

with coeliac

disease. The Lancet, 307(7958), 506-508.

15. Reinertsen, J. L., Klippel, J. H., Johnson, A. H., Steinberg, A. D., Decker, J. L., \& Mann, D. L. (1978). B-lymphocyte alloantigens associated with systemic lupus erythematosus. New England Journal of Medicine, 299(10), 515-518.

16. Ghorbel, I. B., Belfeki, N., Jaziri, F., Karoui, S., Smiti, M. K., Miled, M., ... \& Houman, M. (2010). Association lupus érythémateux systémique et maladie cœliaque. À propos de six observations. $L a$ Revue de médecine interne, (31), S446-S447.

17. Zitouni, M., Daoud, W., Kallel, M., \& Makni, S. (2004). Association entre lupus érythémateux systémique et maladie coeliaque: cinq cas. Revue du rhumatisme, 71(7), 630-632.

Cite This Article: Jaouad Yousfi et al (2021). Coexistence of Celiac Disease and Systemic Lupus Erythematosus: A Case Report. East African Scholars J Med Surg, 3(3), 44-46. 